\title{
Enhancing absorption properties of Mg-Ti substituted barium hexaferrite nanocomposite through the addition of MWCNT
}

\begin{abstract}
M-type barium ferrite with Mgï Ti substitution and MWCNT addition was synthesized using high-energy ball milling. The prepared sample was further analyzed using X-ray diffraction, field emission scanning electron microscope (FESEM), vibrating sample magnetometer and vector network analyzer. The results showed that the particle size had a wide range of distribution, and a hexagonal structure was formed in the sample. The sample was observed to have lower saturation magnetization and coercivity after $\mathrm{Mgï} \mathrm{Ti}$ was substituted with MWCNT and added into the barium hexaferrite. Reflection loss was studied as a function of frequency and thickness of the sample. For Mgï Ti substituted barium hexaferrite composite with a thickness of $2.0 \mathrm{~mm}$, the reflection loss peaked at $\bar{\imath} 28.83 \mathrm{~dB}$ at a frequency of 15.57 $\mathrm{GHz}$ with a bandwidth of $6.43 \mathrm{GHz}$ at a loss of less than $\bar{\imath} 10 \mathrm{~dB}$. The microwave absorption primarily resulted from magnetic losses caused by magnetization relaxation, domain wall resonance, and natural resonance. FESEM micrograph demonstrated that carbon nanotubes were attached to the external surface of the ferrite nanoparticles. The investigation of the microwave absorption indicated that with an addition of carbon nanotubes, the real and imaginary parts of permittivity and reflection loss had enhanced to $\bar{\imath} 34.16 \mathrm{~dB}$ at a frequency of $14.19 \mathrm{GHz}$ with a bandwidth of $5.72 \mathrm{GHz}$.
\end{abstract}

Keyword: Mgï Ti; MWCNT; Barium hexaferrite; Absorption 